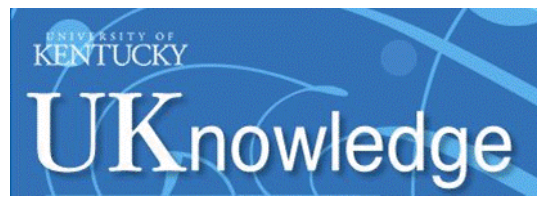

University of Kentucky

UKnowledge

\title{
A Comparative Study of Methods for Calculating AC Winding Losses in Permanent Magnet Machines
}

\author{
Narges Taran \\ University of Kentucky, narges.taran@uky.edu \\ Vandana Rallabandi \\ University of Kentucky, vandana.rallabandi@uky.edu \\ Dan M. Ionel \\ University of Kentucky, dan.ionel@uky.edu \\ Greg Heins \\ Regal Beloit Corporation, Australia \\ Dean Patterson \\ Regal Beloit Corporation, Australia
}

Follow this and additional works at: https://uknowledge.uky.edu/peik_facpub

Part of the Power and Energy Commons

Right click to open a feedback form in a new tab to let us know how this document benefits you.

\section{Repository Citation}

Taran, Narges; Rallabandi, Vandana; Ionel, Dan M.; Heins, Greg; and Patterson, Dean, "A Comparative Study of Methods for Calculating AC Winding Losses in Permanent Magnet Machines" (2019). Power and Energy Institute of Kentucky Faculty Publications. 24.

https://uknowledge.uky.edu/peik_facpub/24

This Conference Proceeding is brought to you for free and open access by the Power and Energy Institute of Kentucky at UKnowledge. It has been accepted for inclusion in Power and Energy Institute of Kentucky Faculty Publications by an authorized administrator of UKnowledge. For more information, please contact UKnowledge@lsv.uky.edu. 


\title{
A Comparative Study of Methods for Calculating AC Winding Losses in Permanent Magnet Machines
}

\author{
Digital Object Identifier (DOI) \\ https://doi.org/10.1109/IEMDC.2019.8785396
}

\section{Notes/Citation Information}

Published in 2019 IEEE International Electric Machines \& Drives Conference (IEMDC).

(C) 2019 IEEE Copyright Notice. "Personal use of this material is permitted. Permission from IEEE must be obtained forall other uses, in any current or future media, including reprinting/republishing this material for advertising or promotional purposes, creating new collective works, for resale or redistribution to servers or lists, or reuse of any copyrighted component of this work in other works."

The document available for download is the authors' manuscript version that is accepted for publication. The final published version is copyrighted by IEEE and will be available as: N. Taran, V. Rallabandi, D. M. Ionel, G. Heins, andD. Patterson, "A Comparative Study of Methods for Calculating AC Winding Losses in Permanent Magnet Machines," 2019 IEEE International Electric Machines and Drives Conference (IEMDC), San Diego, CA, 2019, pp. 1-7. 


\section{A Comparative Study of Methods for Calculating AC Winding Losses in Permanent Magnet Machines}

\author{
Narges Taran \\ SPARK Lab, ECE Dept. \\ University of Kentucky \\ Lexington, KY, USA \\ narges.taran@uky.edu
}

\author{
Vandana Rallabandi \\ SPARK Lab, ECE Dept. \\ University of Kentucky \\ Lexington, KY, USA \\ vandana.rallabandi@uky.edu
}

\author{
Dan M. Ionel \\ SPARK Lab, ECE Dept. \\ University of Kentucky \\ Lexington, KY, USA \\ dan.ionel@uky.edu
}

\author{
Greg Heins \\ Regal Beloit Corp. \\ Research and Development \\ Rowville, VIC, Australia \\ greg.heins@ regalbeloit.com
}

\author{
Dean Patterson \\ Regal Beloit Corp. \\ Research and Development \\ Rowville, VIC, Australia \\ dean.patterson@ regalbeloit.com
}

\begin{abstract}
In this study different methods of estimating the additional ac winding loss due to eddy currents at open-circuit are explored. A comparative study of 2D and 3D FEA, and hybrid numerical and analytical methods is performed in order to recommend feasible approaches to be employed. Axial flux permanent magnet (AFPM) machine case studies are included, namely a machine with open slots and a coreless configuration. These machine topologies are expected to present a substantial amount of ac winding loss, which would therefore need to be considered during optimal design. This study is one of the first ones to compare meticulous 3D FEA models with more approximate, but faster solution methods which can be employed in the optimization process. The study is comprehensive and includes other discussions relevant to the subject matter, including the selection of the number of turns, the effect of the conductor cross section shape, the placement of each turn for the two machines under study, and the meshing of the turns for FEA based methods. Furthermore, the paper also proposes a measurement method for additional open-circuit winding losses.
\end{abstract}

Index Terms-Eddy currents, skin effect, proximity effect, open circuit winding losses, PM machines, axial flux, coreless.

\section{INTRODUCTION}

The eddy currents are the result of exposure to alternating magnetic field and cause additional copper loss and temperature rise. The alternating magnetic field can be due to the ac current inside the same conductor (skin effect), or the ac current flowing in the adjacent conductors (proximity effect). In case of a permanent magnet (PM) excited electric machine, the magnetic field causing eddy currents may also be due to the leakage flux of the rotor PMs passing over the stator coils (open circuit copper loss). This third source of ac copper loss is discussed far less frequently in literature while it can be more significant than the proximity losses [1], [2], especially where frequency is not supper high. Some authors integrate the open-circuit copper loss with the proximity loss [3].

Two axial flux PM (AFPM) machines in which the PM passing loss is the largest source of ac losses in the winding are discussed. The additional conductor loss caused by rotor PMs is more significant in case of open slot machines, due to the increased leakage flux, and an extreme case occurs for air cored machines where the stator core is eliminated and all conductors are exposed to the air gap flux density.

Several authors have analytically estimated the additional ac copper loss [1], [4]-[8]. Two-dimensional FEA is used in many studies [9]-[12] while 3D FEA has been employed only very recently in few works [3], [13]. Hybrid methods for the estimation of skin and proximity effect losses are also investigated in [14]-[16]. Some of the concerns related to the design of electric machines with reduced additional ac copper loss have been addressed for example in [9], [17].

This paper further contributes to the subject matter by studying AFPM machines and comparing hybrid numerical and analytical, 2D and 3D FEA approaches of calculating additional ac conductor loss. The comparison of quicker and less accurate methods with meticulous 3D FEA results is especially important for AFPM machines as the 2D models for such machines may be overly simplified considering the 3D flux linkage and leakage flux paths. The case studies include two topologies where significant values of additional copper loss due to the magnet flux is expected, namely, open slot and air cored PM machines. One of the main goals is to assess the accuracy of fast loss estimation methods that are more suitable to be employed in the optimal design of AFPM machines, which requires a large number of design evaluations.

The following section describes the eddy current calculation methods employed in this study. The case studied air cored and the open slot AFPM machine are discussed in section III and IV, respectively. The loss estimation methods are employed and the results are compared. In section $\mathrm{V}$ a measurement approach is proposed and the 3D FEA calculations are validated for the open-slot machine with square conductors. The study concludes in section VI. 


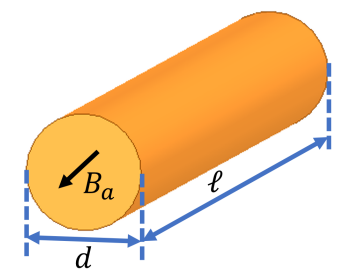

(a)

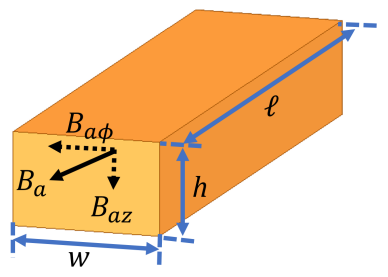

(b)
Figure 1: Illustration of wires with circular and rectangular cross section.

\section{Eddy Loss Calculation Methods}

The analytical methods for calculating eddy current loss, $P_{\text {eddy }}$, have been attempted in several publications. Majority of these approaches originate from the following

$$
P_{e d d y}=\frac{1}{R}\left(\frac{d \phi}{d t}\right)^{2}
$$

where $R$ is the resistance and $\phi$ is the magnetic flux seen by the conductors. It can be shown that for a machine with $N_{c}$ coil sides with the length of $\ell, N_{t}$ turns per coil with circular cross section as shown in Fig. 1a, and $N_{s}$ strands per turn with diameter of $d$, assuming no magnet flux leakage on the end coils and all of the coil region exposed to a space uniform flux density of $B_{a}$ varying sinusoially in time, the eddy current loss can be estimated by

$$
P_{e d d y}=\frac{\pi \ell N_{c} N_{t} N_{s} d^{4} B_{a}^{2} \omega^{2} \sigma}{128},
$$

where $\omega$ is the electrical angular speed and $\sigma$ is the conductivity of the coil. Similarly, for the case with rectangular cross section conductors in Fig. 1b, these losses can be calculated as

$$
P_{e d d y}=\frac{\ell N_{c} N_{t} N_{s} w h \omega^{2} \sigma}{24}\left(w^{2} B_{a z}^{2}+h^{2} B_{a \phi}^{2}\right),
$$

where $B_{a z}$ and $B_{a \phi}$ are the axial, in $z$ direction, and tangential, in $\phi$ direction, component of the flux density as shown in Fig. 1b. The assumption of uniform $B_{a}$ in many cases is not accurate due to skin effect, larger leakage flux at the top of the slots, circulating currents in parallel conductors, etc. The accuracy of simple calculations such as (2) and (3), varies for different machine structures. For example, in machines where conductors are placed in slots, each turn experiences a different flux density. Also, if the conductor diameter is significantly larger than skin depth, the variation of $B_{a}$ inside each turn is considerable.

For machines with conductors placed in slots, hybrid numerical and analytical methods may be more feasible to employ in optimization due to the faster solution time. Such mthodes obtain $B_{a}$ via magnetostatic numerical methods and then use it in analytical equations [14], [15]. In hybrid methods, especial care is required in determining the sampling points for acquiring the flux density distribution throughout the coil cross section. This is also important in cases where the coil pitch to pole pitch ratio is varying with diameter, which may

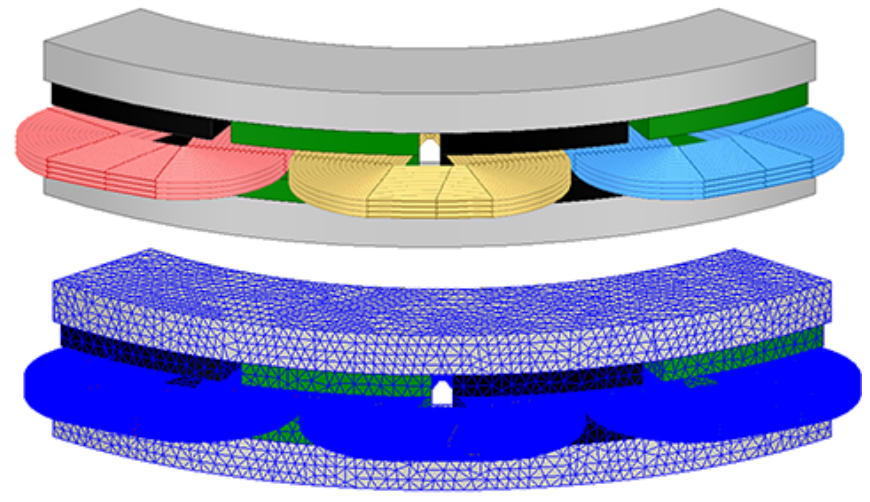

Figure 2: The 3D model of the coreless machine under study. Each turn is separately modeled and meshed.

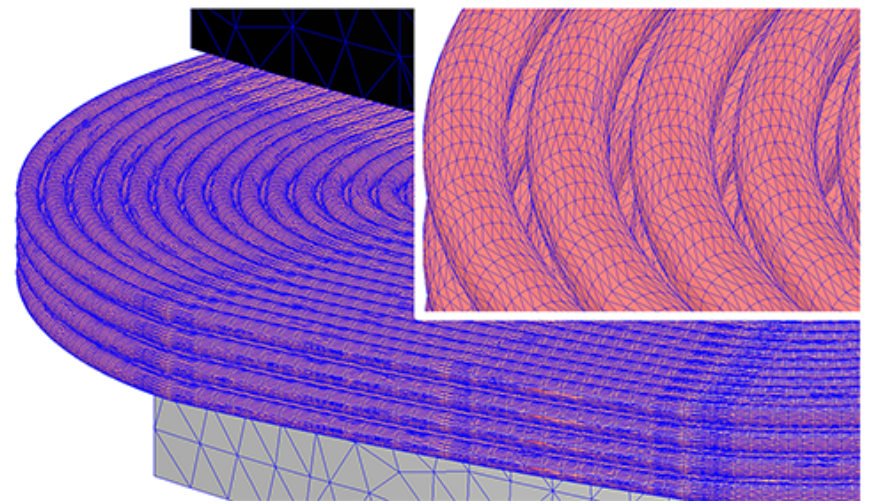

Figure 3: A zoomed view of the tetrahedral meshes in the conductors of the coreless machine from Fig. 2.

be the case for air-cored machines as the conductors position is not constrained by stator teeth and slots.

This paper compares three methods of calculating opencircuit eddy current winding losses for different case studies. These include; 1) hybrid method that analytically calculates the losses employing equation (2) with the flux density obtained from a general 2D FEA model, without any detailed turns modeling; 2) detailed 2D FEA; and 3) detailed 3D FEA with meticulous turn-by-turn models.

If all the conductors are modeled and meshed correctly considering the skin depth, the mesh size would be very large (over 8 million elements in the case studies considered here). This necessitates use of high performance computing (HPC) systems and supercomputers. Another approach could be to fine mesh only the turns that cause the majority of the losses. For instance, as it will be shown, for the open-slot AFPM machine most of these losses happen at the top three layers of the winding. Therefore, the rest of the turns can be meshed coarsely.

\section{Case Study 1: Air Cored Axial Flux PM MACHINE}

Air-cored PM machines (also known as coreless or ironless electric machines) are attractive options for high speed applications due to the elimination of the stator core loss. On 
the other hand, all the conductors are exposed to the air-gap flux density hence have larger eddy currents, which is more critical at higher speeds. This forces the application of thinner conductors and a larger number of turns and strands, necessitating the consideration of expensive Litz wires. Therefore the estimation of ac copper loss in the design stage in air-cored machine topologies is of utmost importance.

The axial component of flux density in AFPM air-cored configurations can be calculated reasonably accurately [18], [19] using the following

$$
B_{a z}=\sum_{\nu=1}^{\infty} B_{\nu} \cosh \left(\frac{\nu \pi}{\tau_{p}} z\right) \cos \left(\nu \phi \frac{p}{2}\right)
$$

where $\phi$ is the angular position of the conductor; $z$ axial position of the conductor, $B_{\nu}$ maximum flux density of the $\nu^{\text {th }}$ harmonic, $\tau_{p}$ pole pitch, $p$ number of poles. This makes the use of fast and pure analytical methods for air cored machines more convenient.

The exemplified coreless machine in this study is shown in Fig. 2 and Fig. 3. For this 16 pole machine with 12 air-cored coils it was estimated that 72 turns can give the desired torque constant. All turns are in series and Litz wire application is not included. In order to calculate the winding losses using the hybrid method, a general time transient 2D FEA model is analyzed and flux density values are sampled in the coordinates of the center of each turn. The flux density is obtained by recording the variation of flux density in time.

Due to the axial symmetry shown in Fig. 4 and Fig. 5 the flux density observed by points 1 and 4 , and also points 2 and 3 are the same. Furthermore, due to the rotation of the rotor, modeling the flux density variation with time for a single column of turns is sufficient. This indicates that modeling only 2 turns may suffice. This is especially interesting in case of the detailed and computationally expensive FEA models [20]. Considerable reduction in computational efforts and mesh size (90\% less number of mesh elements) is achieved by modeling only two turns for the coreless machine case study without affecting the accuracy of the results. It should be noted that such approaches for reducing the modeling efforts are applicable for eddy current loss calculation at open-circuit or cases where proximity effects are not considerable and the eddy losses are mostly caused by the magnet flux.

The copper loss at open circuit is calculated with three methods for the coreless machine. The hybrid method estimates about $520 \mathrm{~W}$ of ac copper loss, while 2D and 3D FEA estimate $611 \mathrm{~W}$ and $420 \mathrm{~W}$ respectively. The $2 \mathrm{D}$ model calculates the flux density in the copper at the mean diameter where it is the maximum, while closer to the ends the flux density would have reduced, as shown in Fig. 6a. Considering that the eddy current losses are proportional to the square of the flux density, the overestimated flux by the 2D model can cause such a significant difference between $2 \mathrm{D}$ and $3 \mathrm{D}$ results. Example 2D FEA results including conductor flux density and current density are shown in Fig. 7.

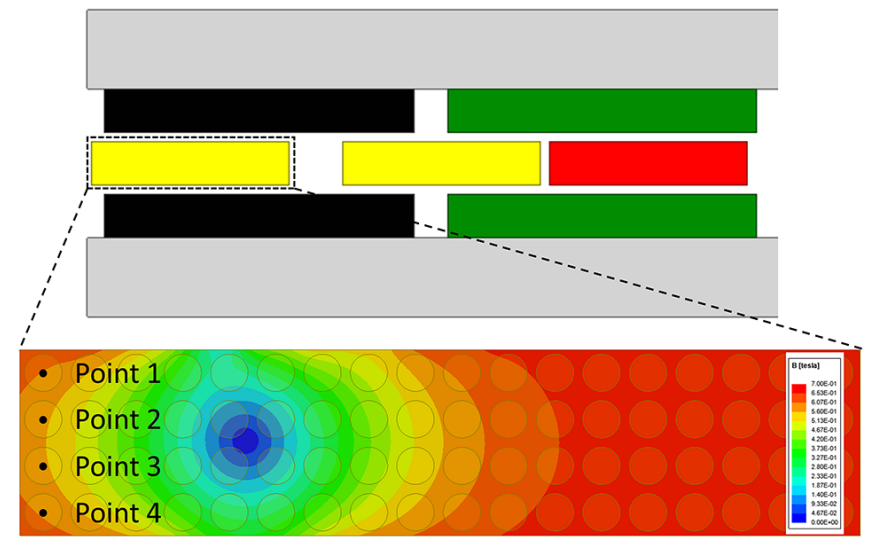

Figure 4: The general 2D model for sampling flux density values employed in the hybrid method. The coil cross section marked with dashed box is zoomed in to show the location of four sampling points in the center of round conductors.

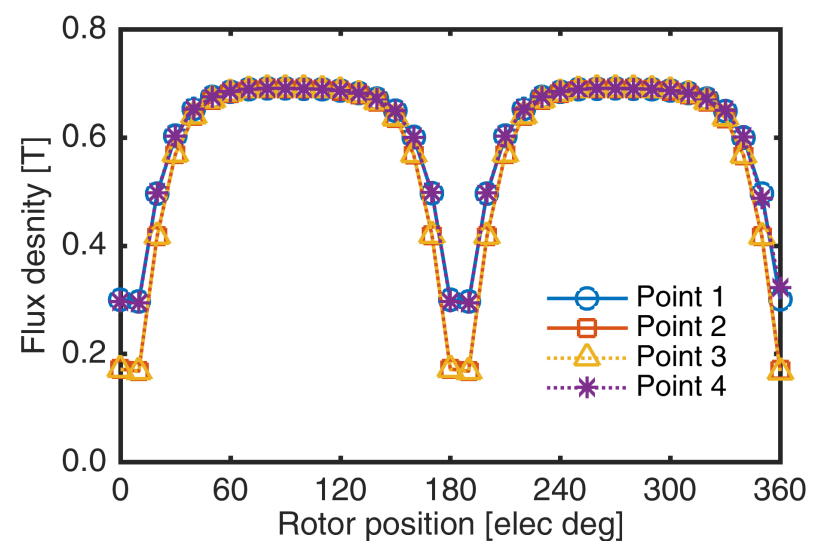

Figure 5: The flux density in the sampling points shown in Fig. 4 at different time steps.

This over-estimation can also be partly attributed to neglecting the end turns in the eddy current path by 2D FEA and hybrid method. The end turns add to the resistance and reduce the eddy currents. Moreover, the coreless machine can be designed with varying coil pitch to pole pitch ratio with diameter, for various reasons such as making maximum use of space for conductors. Such effects cannot be captured by common 2D models and utilization of correction factors and/or quasi-3D models is recommended.

The calculation outcomes show that the coreless topology within the ratings and constraints of this study, results in a low efficiency performance. From the engineering point of view it points out that an entire new technology such as Litz wire needs to be employed. Therefore, further studies for selecting number of turns and twisted strands and their placement, taking the high cost of Litz wire technology into account, needs to be carried out [21], [22]. The remainder of the paper is dedicated to more conventional cases with ferromagnetic core. 


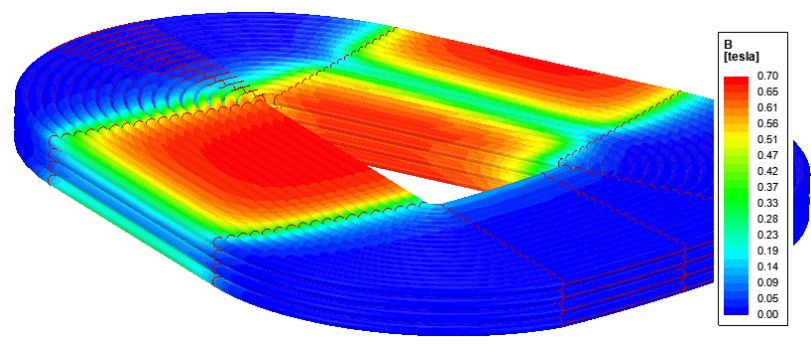

(a)

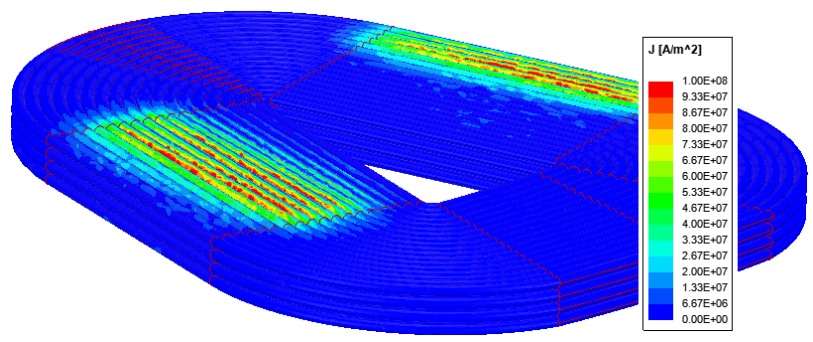

(b)

Figure 6: (a) Flux density obtained from the 3D FEA model of the coreless machine case study, illustrating the lower values closer to the end turns. (b) The current density distribution.

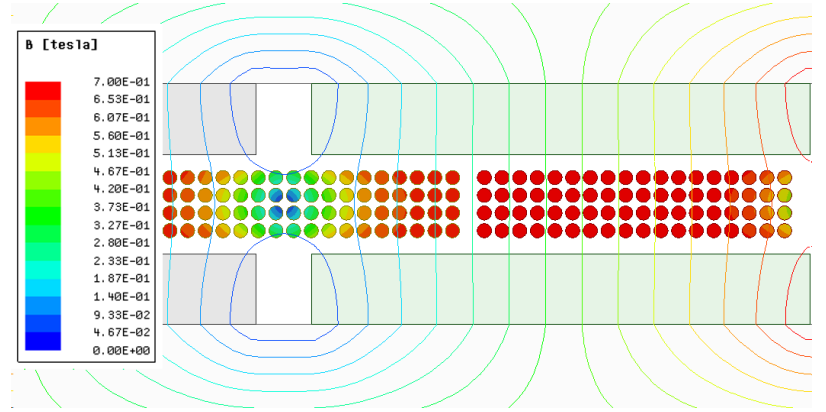

(a)

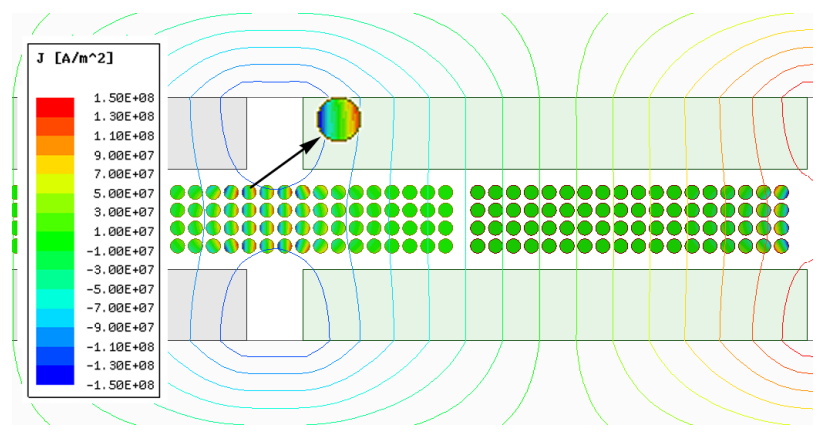

(b)

Figure 7: The 2D FEA model of the coreless machine under study: (a) flux density distribution and (b) current density distribution in conductors at opencircuit operation.

\section{Case Study 2: Open Slot Stator Core Axial FLUX PM MACHINE}

The second case study is an AFPM machine that employs a stator core with open slots. The 3D model of the optimally designed topology is presented in Fig. 8. The open slot

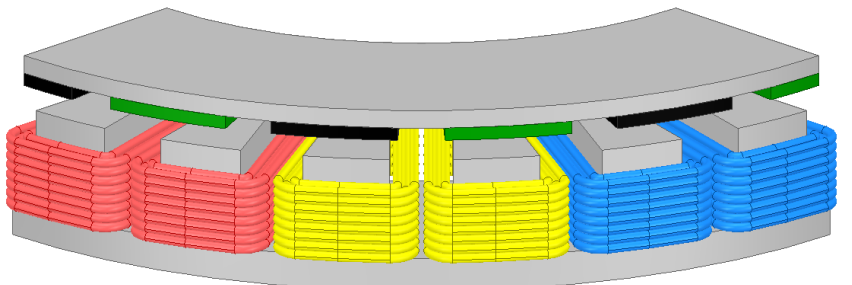

Figure 8: The 3D FEA model of the AFPM machine under study with open slot stator core.

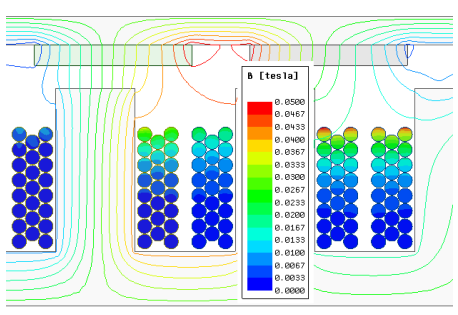

(a)

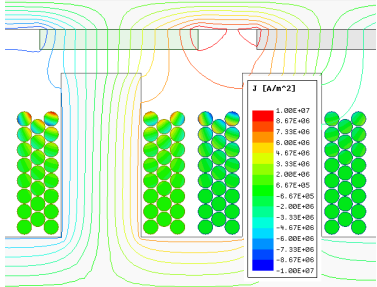

(b)
Figure 9: The 2D FEA model of the optimally designed AFPM machine with open slot stator core in which the circular conductors are utilized and placed further away from the slot opening: (a) flux density distribution and (b) current density distribution in conductors at open-circuit operation.

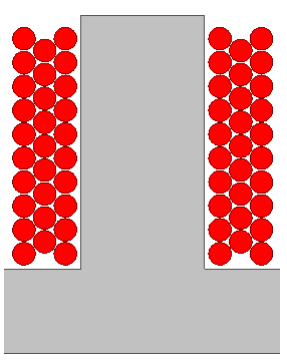

(a)

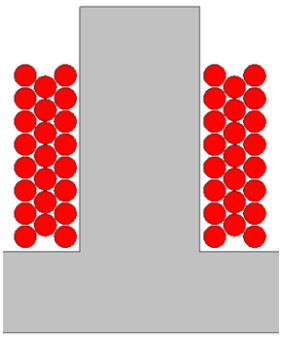

(b)

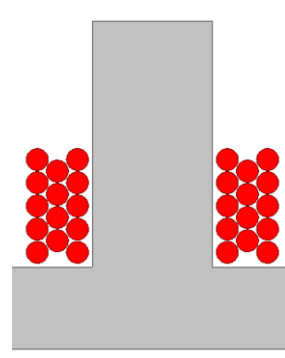

(c)
Figure 10: The open slot bound coils with (a) 29 turns, (b) 23 turns, and (c) 14 turns.

machines due to their larger flux leakage, are prone to eddy currents and additional copper loss. The turns located on top of the slot experience larger flux density and hence have higher loss. Therefore each turn has a separate $B_{a}$ which may not be uniformly distributed, necessitating separate calculation and data sampling for each turn.

Larger flux density and hence eddy current for conductors closer to the slot opening can be observed in Fig. 9. The eddy current losses can be reduced by placing conductors further away from the slot opening, Fig. 10. However, this reduces slot fill factor and hence requires increasing the current density and dc copper loss. The number of turns can be selected based on this trade-off between dc and additional ac copper losses. For this case study, the number and placement of the turns is selected to achieve the minimum copper losses at the rated frequency. The calculations are performed for different number of turns. As seen in Fig. 11, in this machine, 23 turns achieve 


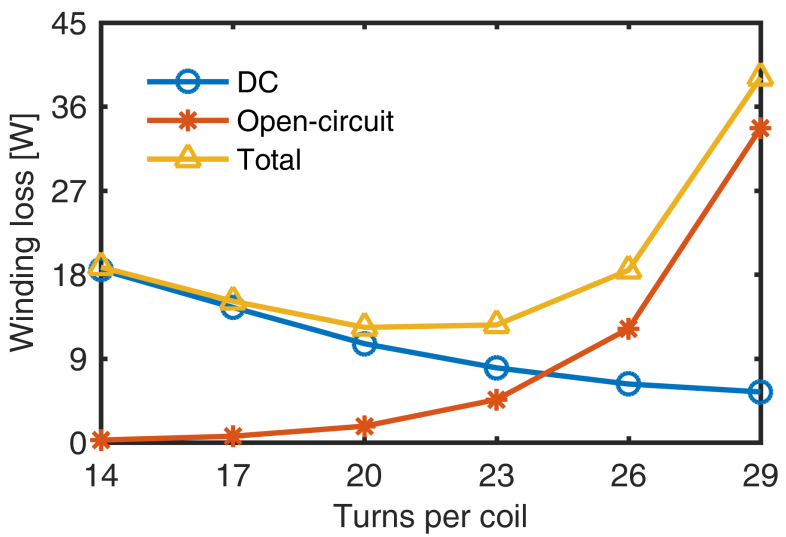

Figure 11: The winding dc and additional open-circuit eddy current ac losses with different number of turns at rated load.

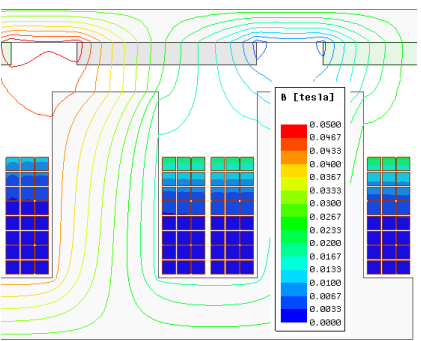

(a)

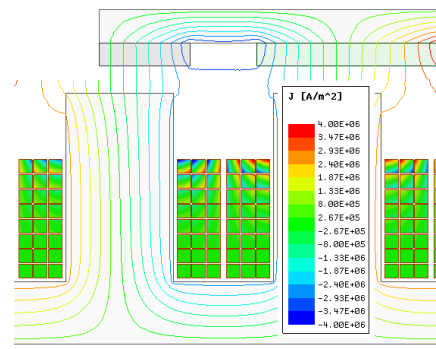

(b)
Figure 12: The 2D FEA model of the AFPM machine with open slot stator core, employing square conductors: (a) flux density distribution and (b) current density distribution in conductors at open-circuit operation. Note the reduction in flux density and current density compared to circular conductors in Fig. 9.

the best balance between dc and ac components of copper losses. Other solutions, such as the use of larger number of strands with smaller cross section can reduce the ac component of the copper loss, while reducing the fill factor and increasing the cost.

Another solution to reduce only the ac copper losses without increasing other losses is to employ conductors with square cross section, as shown in Fig. 12. The square shape of the wires helps in condensing the coil for the same overall conductor area, thus making it possible to locate the conductors further away from the air-gap, while maintaining the same dc copper losses. For this case study, the square wire dimensions are selected to give the same overall conductor area as the circular wires. The amount of reduction in losses for the machine under study is presented in Fig. 13. For this example study, it was observed that if the conductors with square cross section are placed at the same slot depth as the circular one, the overall conductor losses reduces due to greater slot fill factor, although the eddy current losses in both types of conductors are the same.

Similar to case study 1, three methods of eddy loss calculation are employed. The hybrid method obtains the flux density observed by each turn from a time transient general 2D FEA model. Detailed 2D and 3D FEA are also used to

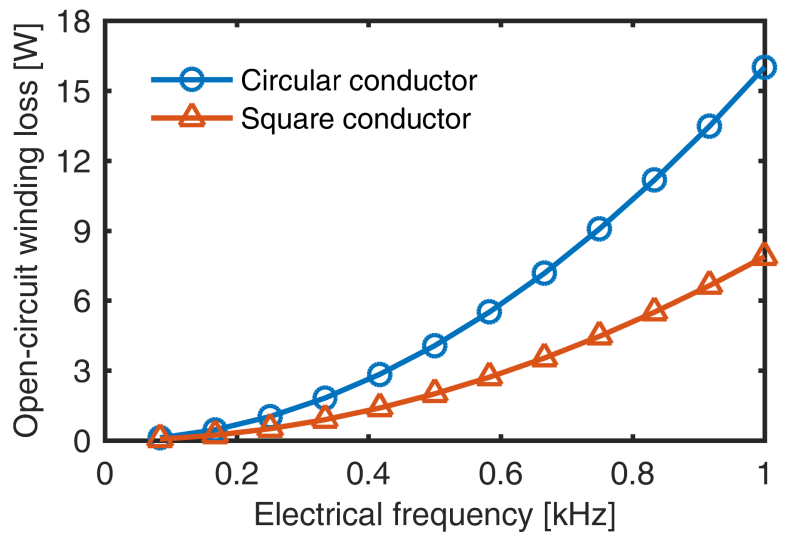

Figure 13: The additional eddy current copper losses at open circuit calculated with FEA for cases with circular and square conductors. The overall conductor area in both cases is maintained the same.

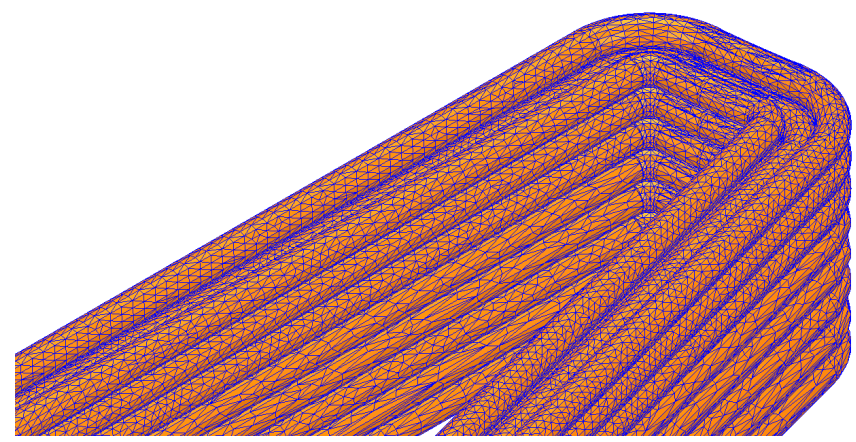

Figure 14: The mesh for the coil in the case study of the open slot AFPM machine. The turns closer to the slot opening are meshed finer.

compare the results. The mesh plot in Fig. 14 shows fine mesh for the turns closer to the slot opening and coarser mesh for the conductors located deeper in the slot. This reduces the computational efforts while maintaining the accuracy of the results.

The ac copper loss calculations using different methods for this case study are $4.2 \mathrm{~W}, 4.4 \mathrm{~W}$, and $3.8 \mathrm{~W}$ with the hybrid method, the 2D FEA, and the 3D FEA, respectively. Good agreement between the three methods is observed. The slightly higher loss predicted by 2D FEA is attributed to the higher flux density estimation as the fringing and leakage at the ends are not captured while 3D FEA as seen in Fig. 15, is capable of taking the end effects into account.

\section{EXPERIMENTAL STUDY}

The experiments and FEA validation is performed for a prototype AFPM machine with open slot and square conductors. The 3D FEA can be done by meshing all the conductors or only the top conductors that are responsible for the majority of the losses, as illustrated in Fig. 16. The computational efforts can be reduced without significant effect on the FEA results.

The separation of loss components, particularly ac and dc copper losses is a difficult task [3], [9], [11], [20]. The proposed method for open-circuit copper loss involves mea- 


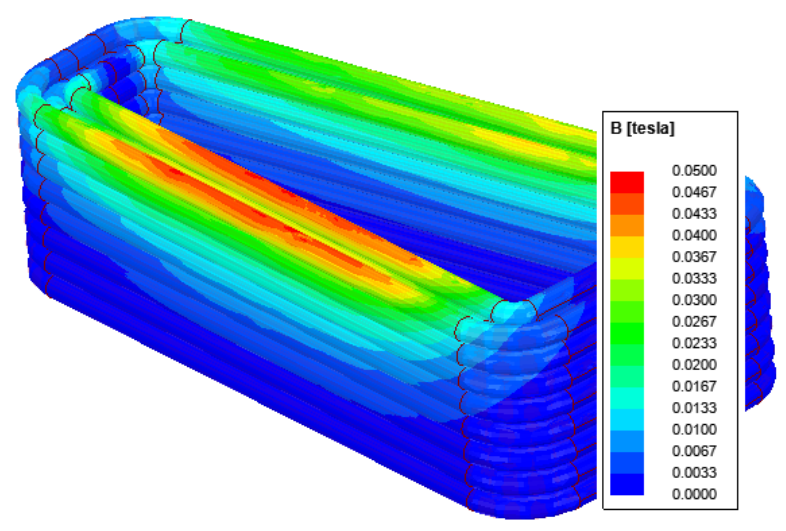

(a)

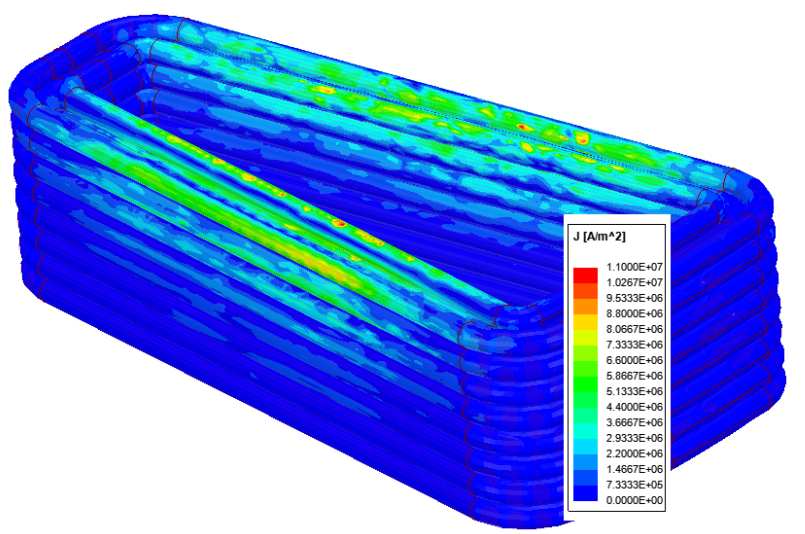

(b)

Figure 15: (a) The flux density observed by the conductors. The reduced flux density at the ends is due to the fringing and leakage. (b) The current density distribution.

surements performed with two distinct coil placements that have different clearances from the top of the slot.

First, the coils are placed closer to the air-gap by the help of 2 spacers. The motor with a spacer implementation is shown in Fig. 17. Then the spacers are removed, as shown in Fig. 18 , the coils are placed at the bottom of the slot. The spinning loss, which includes the mechanical losses, such as friction and windage, stator core losses, open circuit copper, and PM losses, is measured in both scenarios. As confirmed by the numerical computations, the additional copper loss caused by the eddy currents when the conductors are placed further away from the top of the slot is negligible. Therefore the additional (open-circuit) ac copper losses can be calculated by subtracting the two spinning loss measurements. The back EMF was ensured to be the same for the two measurements.

The measurements are performed at different rotational speeds and the results presented in Fig. 19. The FEA estimations are in good agreement with measurement, particularly for the larger speeds where the loss value is larger and hence more feasible to measure.

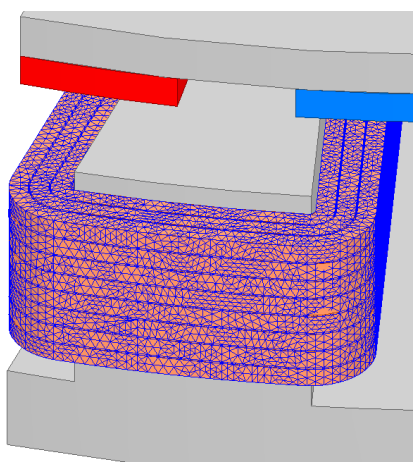

(a)

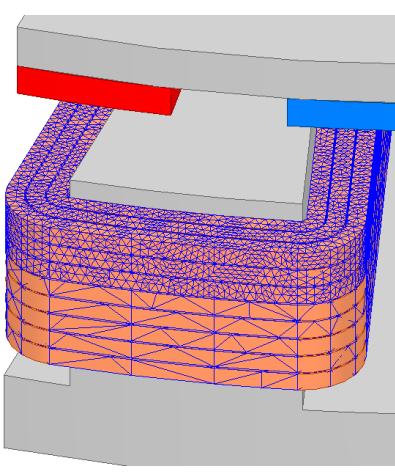

(b)
Figure 16: The 3D model of the prototype machine. The mesh can be fine for (a) all conductors or (b) only for the top conductors that cause the majority of open-circuit eddy current losses.

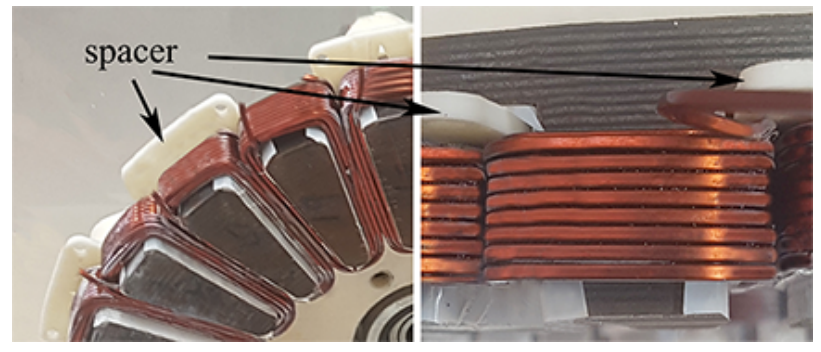

Figure 17: The prototype machine with spacers.
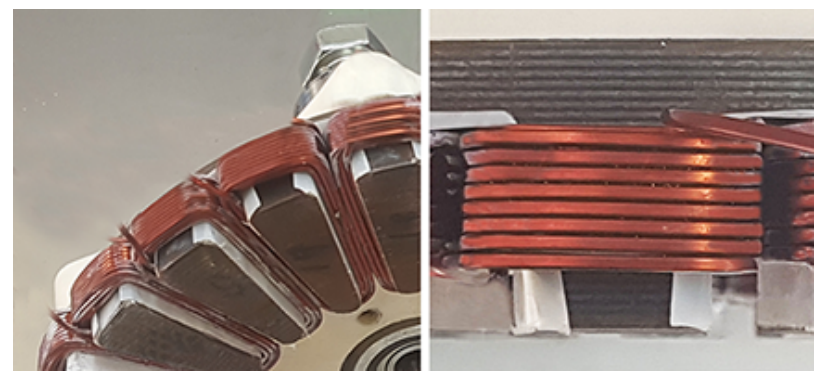

Figure 18: The prototype machine without spacers.

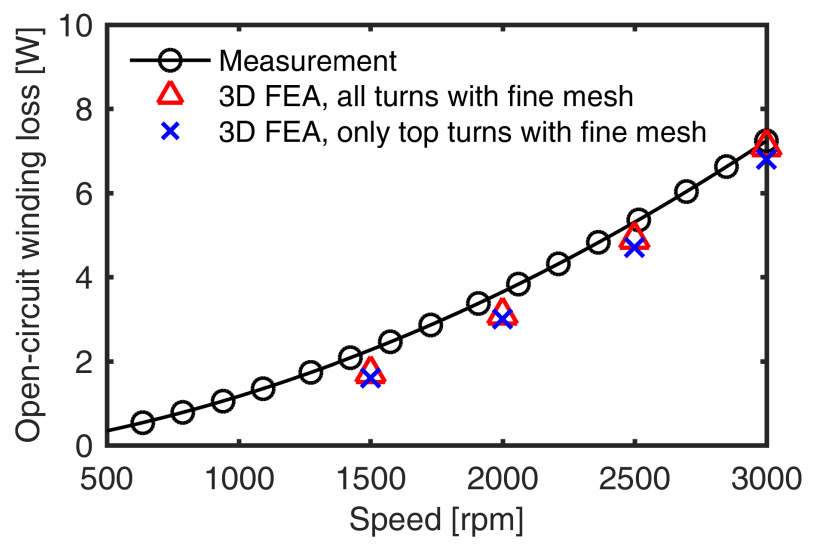

Figure 19: The measurements of ac copper loss and validation of 3D FEA calculations. 


\section{CONCLUSION}

This paper studies hybrid numerical and analytical methods for the calculation of ac losses in conductors in axial flux permanent magnet machines. Certain types of AFPM machines, feature a substantial amount of ac conductor loss, and as such, this should be taken into account during the design optimization stage. The determination of the optimal design requires a large number of computations, and thus, there is a need for a fast method to accurately evaluate these losses.

Comparative study is conducted for three calculation methods, including hybrid analytical and numerical, 2D FEA, and 3D FEA. A case study coreless AFPM machine is discussed which is an extreme case where all the conductors are exposed to the air-gap flux density, hence large eddy currents are expected. The other case includes AFPM machine with open slot, where the leakage flux may result in significant additional loss for the conductors close to the slot opening. This machine is prototyped with square conductors and an eddy current loss measurement approach is proposed.

It is found that the hybrid method, which uses the flux density variation across the conductors obtained using general 2D FEA in analytical equations yields results close to the detailed time transient 2D FEA. The more accurate and computationally expensive 3D FEA results are close to other methods particularly for the open slot AFPM machine. This suggests that for estimating the magnet passing eddy current losses of the machine with stator core the 3D FEA may not be required and the approximate methods may be acceptable. The coreless structure with larger values of eddy loss requires utilization of 3D FEA to take the 3D effects of the AFPM structure into account.

An approach for the measurement of ac winding loss is proposed and conducted for an open slot AFPM machine. The measurements are in close agreement with the results from 3D FEA. Other matters discussed are the selection of the number of turns, the comparison of circular and square conductors, and approaches for reducing mesh size and hence FEA computational time.

\section{ACKNOWLEDGMENT}

The support of Regal Beloit Corporation, University of Kentucky, the L. Stanley Pigman endowment and the SPARK program, and ANSYS Inc. is gratefully acknowledged.

\section{REFERENCES}

[1] L. J. Wu and Z. Q. Zhu, "Simplified analytical model and investigation of open-circuit ac winding loss of permanent-magnet machines," IEEE Transactions on Industrial Electronics, vol. 61, no. 9, pp. 4990-4999, Sept 2014.

[2] P. Ponomarev, I. Petrov, J. Pyrhonen, and N. Bianchi, "Additional losses in stator slot windings of permanent magnet synchronous machines," 2015, doi:10.13140/RG.2.1.2081.9368.

[3] A. Al-Timimy, P. Giangrande, M. Degano, M. Galea, and C. Gerada, "Investigation of ac copper and iron losses in high-speed high-power density PMSM," in 2018 XIII International Conference on Electrical Machines (ICEM), Sept 2018, pp. 263-269.
[4] D. C. Hanselman and W. H. Peake, "Eddy-current effects in slot-bound conductors," IEE Proceedings - Electric Power Applications, vol. 142, no. 2, pp. 131-136, March 1995.

[5] C. R. Sullivan, "Computationally efficient winding loss calculation with multiple windings, arbitrary waveforms, and two-dimensional or threedimensional field geometry," IEEE Transactions on Power Electronics, vol. 16, no. 1, pp. 142-150, Jan 2001.

[6] L. J. Wu, Z. Q. Zhu, D. Staton, M. Popescu, and D. Hawkins, “Analytical model of eddy current loss in windings of permanent-magnet machines accounting for load," IEEE Transactions on Magnetics, vol. 48, no. 7, pp. 2138-2151, July 2012.

[7] P. Zhang, G. Y. Sizov, J. He, D. M. Ionel, and N. A. O. Demerdash, "Calculation of magnet losses in concentrated-winding permanent-magnet synchronous machines using a computationally efficient finite-element method," IEEE Transactions on Industry Applications, vol. 49, no. 6, pp. 2524-2532, Nov 2013.

[8] M. R. Shah and A. M. EL-Refaie, "Eddy-current loss minimization in conducting sleeves of surface pm machine rotors with fractionalslot concentrated armature windings by optimal axial segmentation and copper cladding," IEEE Transactions on Industry Applications, vol. 45, no. 2, pp. 720-728, March 2009.

[9] P. H. Mellor, R. Wrobel, and N. McNeill, "Investigation of proximity losses in a high speed brushless permanent magnet motor," in Conference Record of the 2006 IEEE Industry Applications Conference Forty-First IAS Annual Meeting, vol. 3, Oct 2006, pp. 1514-1518.

[10] M. Popescu and D. G. Dorrell, "Proximity losses in the windings of high speed brushless permanent magnet ac motors with single tooth windings and parallel paths," IEEE Transactions on Magnetics, vol. 49, no. 7, pp. 3913-3916, July 2013.

[11] D. A. Gonzalez and D. M. Saban, "Study of the copper losses in a highspeed permanent-magnet machine with form-wound windings," IEEE Transactions on Industrial Electronics, vol. 61, no. 6, pp. 3038-3045, June 2014.

[12] I. Petrov, M. Polikarpova, P. Ponomarev, P. Lindh, and J. Pyrhönen, "Investigation of additional ac losses in tooth-coil winding pmsm with high electrical frequency," in 2016 XXII International Conference on Electrical Machines (ICEM), Sept 2016, pp. 1841-1846.

[13] N. Aliyu, G. Atkinson, N. Stannard, and M. Kimiabeigi, "Assessment of $\mathrm{AC}$ copper loss in permanent magnet axial flux machine with soft magnetic composite core," in 2018 IX International Conference on Power Electronics Machines and Drives (PEMD), Apr 2018.

[14] G. Volpe, M. Popescu, F. Marignetti, and J. Goss, "Modelling ac winding losses in a pmsm with high frequency and torque density," in 2018 IEEE Energy Conversion Congress and Exposition (ECCE), Sept 2018, pp. 2300-2305.

[15] A. Fatemi, D. M. Ionel, N. Demerdash, D. A. Staton, R. Wrobel, and Y. C. Chong, "Computationally efficient strand eddy current loss calculation in electric machines," IEEE Transactions on Industry Applications, pp. 1-1, 2019.

[16] O. A. Mohammed and S. Ganu, "FE-circuit coupled model of electric machines for simulation and evaluation of EMI issues in motor drives," IEEE Transactions on Magnetics, vol. 46, no. 8, pp. 3389-3392, Aug 2010.

[17] C. R. Sullivan, "Optimal choice for number of strands in a litz-wire transformer winding," IEEE Transactions on Power Electronics, vol. 14, no. 2, pp. 283-291, March 1999.

[18] N. Taran, V. Rallabandi, G. Heins, and D. M. Ionel, "Coreless and conventional axial flux permanent magnet motors for solar cars," IEEE Transactions on Industry Applications, vol. 54, no. 6, pp. 5907-5917, Nov 2018.

[19] N. Chayopitak and D. G. Taylor, "Performance assessment of air-core linear permanent-magnet synchronous motors," IEEE Transactions on Magnetics, vol. 44, no. 10, pp. 2310-2316, Oct 2008.

[20] G. Heins, D. M. Ionel, D. Patterson, S. Stretz, and M. Thiele, "Combined experimental and numerical method for loss separation in permanentmagnet brushless machines," IEEE Transactions on Industry Applications, vol. 52, no. 2, pp. 1405-1412, March 2016.

[21] C. R. Sullivan, "Cost-constrained selection of strand diameter and number in a litz-wire transformer winding," IEEE Transactions on Power Electronics, vol. 16, no. 2, pp. 281-288, March 2001.

[22] B. A. Reese, R. Joseph, and C. R. Sullivan, "Improved litz-wire designs for the mhz range," in 2018 IEEE 19th Workshop on Control and Modeling for Power Electronics (COMPEL), June 2018, pp. 1-8. 